\title{
Uma revisão crítica das fontes historiográficas para a história do Império Parto (247 a.C. - 228 d.C.): o caso de Apolodoro de Artemita e Arriano de Nicomédia
}

\author{
A Critical Review of the Historiographical Sources for the History of \\ the Parthian Empire (247 B.C. - 228 A.D.): the Case of Apollodorus of \\ Artemita and Arrian of Nicomedia
}

\author{
Henrique Modanez de Sant'Anna \\ henriquemodanez@gmail.com \\ Professor Adjunto \\ Universidade de Brasília \\ SQN 214, bloco D, ap. 410 - Asa Norte \\ 70873-040 - Brasília - DF \\ Brasil
}

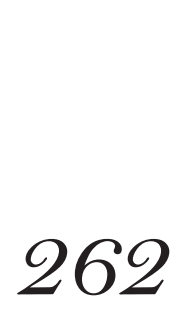

\section{Resumo}

Este artigo está vinculado ao crescente interesse crítico pelo Império Parto e tem como objetivo discutir duas das principais fontes historiográficas para a história dessa unidade política nascida em 247 a.C., após a vitória militar sobre os selêucidas: Apolodoro de Artemita e Arriano de Nicomédia. A escolha desses dois historiadores antigos (cada qual com sua Parthica) deve-se aos fatos de que Apolodoro foi o primeiro a registrar a manipulação da ancestralidade aquemênida pelos partos, como parte de sua estratégia de legitimação política, e de que Arriano se tornou o principal herdeiro da historiografia greco-parta (representada por Apolodoro) na tradição literária romana.

\section{Palavras-chave}

Fonte histórica; Grécia Antiga; Historiografia antiga.

\begin{abstract}
This article is linked to the awakening of critical interest in the Parthian Empire and aims at discussing two of the main historiographical sources for the history of this political unity established in 247 B.C. after a military victory over the Seleucids: Apollodorus of Artemita and Arrian of Nicomedia. The selection of these two ancient historians (both authors of a Parthica) is due to the facts that Apollodorus was the first to record the manipulation of the Achaemenid ancestry by the Parthians as part of their strategy of political legitimation, and that Arrian became the main author to inherit the Greco-Parthian historiography (represented by Apollodorus) in the Roman literary tradition.
\end{abstract}

\section{Keywords}

Historical source; Ancient Greece; Ancient historiography. 
[Os partos] pagavam seus tributos com os hircânios enquanto estavam sob o jugo persa, e da mesma forma o fizeram posteriormente, quando por muito tempo os macedônios detiveram o poder. [...] Nos dias atuais, no entanto, os partos governam tantos territórios e tantas tribos que, na dimensão de seu Império, eles se tornaram rivais dos romanos. A causa disso é seu estilo de vida, mas também seus costumes, que contêm muito do estilo bárbaro e cita, embora mais propensos à unidade política e ao sucesso na guerra.

Estrabão, Geografia XI, 9.

[Os partos] repeliram os macedônios, estabeleceram um governo próprio e se tornaram tão poderosos que eram páreo para os romanos na guerra, algumas vezes sendo até capazes de derrotá-los.

Fócio, Myrobiblion $=$ FGrH 156, F 30.

Recentemente, Curtis e Stewart (2007, pp. 1-2) chamaram a atenção para a visão negativa da representação artística parta, exemplificada com nitidez nos comentários pouco amistosos de Herzfeld no início da década de $1940 .{ }^{1}$ Tal situação seria o resultado dos seguintes fatores: 1 ) a era e a arte parta foram objetos de análise principalmente de classicistas que as observaram do ponto de vista da arqueologia clássica e da arte helenístico-romana; 2) a arqueologia do Oriente Próximo mostrou-se especialmente preocupada com os níveis mais antigos dos sítios arqueológicos, ignorando por vezes estruturas pertencentes ao período Arsácida em prol do Aquemênida, medo e elamita, no Irã, e do assírio e babilônio, na Mesopotâmia.

De acordo com Daryaee (2009, p. 587), na segunda metade do século XX a história do Irã antigo tornou-se objeto de intenso estudo, deixando para trás muitas das conclusões alcançadas por autores como Herzfeld (1941), sobre a arte parta, e Debevoise (1938), Christensen (1944) e Olmstead (1959), sobre a história dos Arscácidas, Sassânidas e Aquemênidas, respectivamente. A grande virada veio com a descoberta do arquivo de Persépolis e com os textos rituais aramaicos, que mudaram a percepção até então vigente sobre a história Aquemênida. Além desses documentos, há que se referenciar também o avanço da pesquisa em documentos egípcios, elamitas e babilônios, produto desse novo esforço para entender com mais ferramentas metodológicas uma realidade por muito tempo negligenciada pelos historiadores.

Considerando tamanho avanço na área da Iranologia nas décadas recentes, cabe a realização de duas perguntas iniciais em termos historiográficos: 1) que fontes primárias (especialmente historiadores antigos) podem ser consultadas para a história do Império Parto?; 2) que tipo de análise historiográfica pode ser feita de Apolodoro e Arriano (um dos últimos autores romanos a consultar

\footnotetext{
1 "Quando os iranianos tentaram aceitar tudo o que era grego, como fazem com tudo o que é europeu, eles não captaram a importância e a proporção, ficando inteiramente satisfeitos com a semelhança. A profundidade das coisas permaneceu oculta para eles. O resultado é uma arte híbrida, se é que se pode chamar arte, que não é nem grega, nem iraniana; não possui valor interior ou estético, e é interessante de se estudar apenas por interesse histórico ou psicológico... É incrível ver quão rapidamente, em não mais do que duas ou três gerações, um trabalho de força ilimitada pode ser completamente perdido, e também o julgamento artístico, com a mera habilidade técnica" (HERZFELD 1941, p. 286-287).
} 
a "tradição de Apolodoro"; cf. infra), tendo como base os fragmentos do que escreveram sobre os partos?

\section{O Império Parto preservado em fontes (primárias)}

A grande dificuldade na escrita da história do Irã antigo, especificamente do período parto, advém do fato de as fontes iranianas serem escassas e de muitas outras histórias terem sobrevivido apenas em fragmentos. De fato, o que sabemos da história dos partos e de sua vida política, social, religiosa e cultural depende diretamente de um entendimento correto acerca da natureza das fontes históricas que temos à disposição (DABROWA 2012, p. 21). Assim, diante da particularidade das fontes antigas para os partos, tem-se sugerido a organização das evidências em dois tipos: vestígios e tradições (WIDENGREN 2007, p. 1261-1262).

Os vestígios são normalmente divididos em textuais e não textuais, sendo os últimos de domínio da arqueologia (ruínas de construções, fortes, pontes, canais etc.) e os primeiros de todas as áreas (incluindo algumas especialidades da arqueologia) ligadas diretamente ao trabalho com inscrições, pergaminhos, papiros e ostraca escritos em vários idiomas. O trabalho epigráfico, por exemplo, permite um entendimento mais sofisticado das línguas usadas nos documentos e da vida cotidiana, visto que o conteúdo (especialmente jurídico, administrativo e econômico) das inscrições permite a análise do material por arquivos de natureza distinta (pessoais, familiares ou ligados aos templos).

264 sobre as línguas empregadas, pode-se ressaltar que da chamada "inscrição georgiana", por exemplo, muitos avanços foram feitos no estudo do idioma parto, quando se descobriu que, ao menos nessa inscrição, o parto se apropriou de formas e palavras aramaicas como ideogramas (cf. HENNING 1958 para um estudo completo sobre o assunto). ${ }^{2}$

Ao lado dos vestígios, encontram-se as chamadas tradições (WIDENGREN 2007, p. 1264), divididas convenientemente em primárias e secundárias. Essas tradições correspondem, no caso da história parta, às fontes sobre as quais o historiador normalmente se debruça, e por isso podemos chamá-las de "primárias" e "secundárias" (suprimidas neste artigo devido ao seu escopo), embora a linha que as separe seja por vezes muito tênue. ${ }^{3}$

Antes de tratar mais especificamente dos fragmentos de Apolodoro e Arriano, cabe destacar que informações importantes sobre os partos podem também ser encontradas em Políbio (Histórias x, 27-31), Isidoro de Cárax (Periégesis da Pártia), Cícero (Carta a Ático v, vi; Cartas Familiares xv) e Salústio (Histórias IV, fr. $69 \mathrm{M})$.

Dentre os autores supracitados, e considerando o caso da historiografia helenística de modo mais particular, Políbio ocupa lugar especial por ter devotado

\footnotetext{
2 A "inscrição georgiana", encontrada na cidade de Armazi (atual Tbilisi, capital da Geórgia), é uma inscrição bilíngue (grego e persa médio) que celebra Serapita e sua linhagem nobre. O tipo de escrita usado na inscrição foi em princípio visto simplesmente como uma modificação do aramaico, até que os avanços supracitados fossem feitos. Para uma discussão mais detalhada sobre as principais descobertas feitas com o avanço dos estudos das fontes (textuais e não-textuais) iranianas, vide WIDENGREN 2007, p. 1262-1263.

${ }^{3}$ Como no caso de Pompeu Trogo, preservado em Justino. Cf. infra.
} 
atenção à política oriental dos selêucidas. Por meio dele (Histórias X, 27-31) temos notícia da expedição de Antíoco III no oriente nos finais do século III a.C., como reação ao movimento separatista parto e seu fortalecimento como reino independente. Em seu relato, Políbio registra, por exemplo, a surpresa de Arsaces ao descobrir que Antíoco, no comando de um exército bastante numeroso, optou pela travessia de um deserto adjacente ao anel de cidades gregas ${ }^{4}$ na Média. Ao tomar tal decisão, Antíoco estaria arriscando enormemente a vida dos seus homens com a falta de água e suprimentos. A rápida, mas preciosa descrição de Políbio sobre os partos, portanto, informa-nos sobre as relações político-militares entre Selêucidas e Arsácidas no momento de consolidação do poderio parto no oriente (DABROWA 2012, p. 22).

Das fontes primárias não-ocidentais, destacam-se o chamado "Hino da Pérola" (fundamental para o entendimento da organização do reino parto antes da conquista da Babilônia), constante do apócrifo Atos de Tomé, a Crônica de Edessa, I Macabeus 14.1-3, II Macabeus 1.13-16, tabuinhas babilônicas escritas com caracteres cuneiformes e os livros chineses de Han ou Han Shu (capítulo 96) e Shih-chi (capítulo 123) (WIDENGREN 2007, p. 1264-1265).

\section{Apolodoro de Artemita}

O Império Parto inspirou autores da tradição narrativa clássica especialmente a partir do século I a.C., quando sua expansão territorial passou a representar uma ameaça ao poderio romano nas fronteiras orientais. Com efeito, na primeira metade do século I a.C., Posidônio de Rodes (135-51 a.C.) dedicou um livro inteiro de suas Histórias aos costumes e às instituições dos partos, no primeiro esforço da literatura grega para realizar um estudo detalhado desse povo. Paralelamente, ou talvez alguns anos mais tarde, ${ }^{5}$ o primeiro trabalho dedicado inteiramente aos partos foi escrito por Apolodoro de Artemita, autor helenístico de origem greco-parta.

De sua atividade autoral, temos notícia apenas da Parthica, que segundo registro de Ateneu (Deipnosofistas XV, 29) era composta de pelo menos quatro livros. Preservada em fragmentos por autores antigos, dos quais destaco Ateneu e Estrabão, ${ }^{6}$ a Parthica de Apolodoro tornou-se conhecida já na Antiguidade pela precisão de suas informações (Estrabão, Geografia II, 5), além de ter fornecido a Estrabão material suficiente sobre as províncias orientais e aquelas situadas ao norte do Império Parto. ${ }^{7}$ Digna de nota é também a seção dedicada aos reis vitoriosos da Báctria, Demétrio (180-165 a.C.) e Menandro (155-130 a.C.), cujas conquistas incluiriam a Índia, superando as do próprio Alexandre. ${ }^{8}$ Dos

\footnotetext{
${ }^{4}$ Criado por Alexandre para proteger a região (Políbio Histórias x, 27).

${ }^{5}$ O problema da datação da obra de Apolodoro é talvez o mais difícil de solucionar. Diferentes datas têm sido sugeridas: em algum momento entre 130 e 87 a.C., de acordo com Tarn (1938, p. 47); nos primeiros trinta anos do século I a.C., segundo Jacoby (Fragmente III C, p. 773); ou entre 66 e 44 a.C., na opinião de Behr (2010, pp. 45-50). A melhor discussão para o assunto é ainda Nikonorov (1998, p. 110-119).

${ }^{6}$ Todos eles reunidos por Jacoby (Fragmente III C, p. 773-76).

7 Cf. Chaumond (2011, p. 160-161) para a lista das províncias e todos os detalhes sobre a geografia da Pártia encontrados nos fragmentos de Apolodoro, preservados por Estrabão.

8 De Apolodoro é provavelmente também a famosa caracterização da Báctria como "a terra das mil cidades" (HOLT 1999, p. 15). Uma obra "clássica" sobre o assunto é Masson (1982).
} 
dois, no entanto, o de maior impacto para a literatura helenística é Menandro, uma vez que este serviu de inspiração para a elaboração de obras posteriores, como As indagações de Rei Milinda, produzida na Índia por volta do início da era cristã (KNIPPSCHILD 2010, p.461).

Apolodoro parece ter igualmente servido de fonte para a redação dos livros quarenta e um e quarenta e dois das Filípicas de Pompeu Trogo, preservados nos Epítomes de Justino, que tratavam da história da Pártia e de outros territórios orientais (HOLT 1999, p.55). A utilização de Apolodoro como fonte para a redação desse material foi sugerida nas décadas de 1940 e 1970 por Altheim (NIKONOROV 1998, pp. 107-108), que defendeu sua hipótese pela sistematização de muitas coincidências geográficas orientais nos relatos de Pompeu Trogo e Estrabão. Como o último declarou a utilização de Apolodoro, tendo elogiado sua precisão na localização dos territórios orientais, parece inegável que Pompeu Trogo tenha, por extensão, lançado mão dos escritos do historiador de Artemita.

Outra questão importante sobre o método de Apolodoro diz respeito às fontes por ele utilizadas para a redação da Parthica. Para Chaumond (2011, p. 161), Apolodoro certamente conhecia os historiadores de Alexandre e geógrafos anteriores, e deles deve ter feito uso frequente. Entretanto, maior atenção deve ser dada ao acesso que possuía, como súdito dos Arsácidas, aos arquivos de cidades greco-partas, como Artemita e Selêucia do Tigre, ${ }^{9}$ sem mencionar, de modo mais dinâmico, compatriotas, mercadores e viajantes.

266 Parece inegável que Apolodoro tenha se beneficiado de sua "condição helenística", com uma identidade construída na "zona cinzenta" entre o grego e o parto/oriental. De fato, nascido e classificado por imersão cultural como grego, Apolodoro ao mesmo tempo se destacava por ter condições de consultar, ler e analisar documentos e textos literários em cuneiforme, aramaico e parto (NIKONOROV 1998, p. 109). Ele, por essa razão, localizava-se "na vanguarda de uma tradição especial da historiografia grega oriental", como quer Nikonorov, o que nos ajuda a contextualizar a afirmação de Estrabão que o identifica como líder de um "grupo de autores de histórias partas":

Que nome é dado aos discípulos de Apolodoro - se membros de uma "escola" ou de um "círculo" - não é importante: mais provavelmente, eles eram historiadores menores da Pártia e dos territórios mais ao oriente, jovens contemporâneos de Apolodoro cujos trabalhos dependiam enormemente de sua Parthica. Estrabão os chama (incluindo o próprio Apolodoro, é claro) de "partos" (1.2.1) - em outras palavras, eles eram, como seu líder, greco-partos. Esses escritores compuseram muitas versões diferentes de um mesmo trabalho original de Apolodoro; talvez tenha sido assim que o material de Apolodoro tornou-se conhecido por autores estrangeiros, como Estrabão, Pompeu Trogo e outros (NIKONOROV 1998, p. 109).

\footnotetext{
9 Uma das grandes capitais helenísticas, em muitos aspectos tão grandiosa quanto Alexandria do Egito. Situada na confluência do Tigre com um grande canal do Eufrates, Selêucia do Tigre (307 a.C.-215 d.C.) era um centro de trocas comerciais vital para a economia helenística, recebendo produtos da Ásia Central, Índia, Pérsia e África.
} 
Apolodoro, então, não escreveu apenas uma das histórias antigas mais importantes sobre o Império Parto, mas também influenciou enormemente membros de uma escola historiográfica que propagou sua obra e a tornou conhecida por autores interessados nos territórios orientais, mais precisamente os que tinham ligação com o poder rival de Roma no oriente. Apolodoro representava para a história do Império Parto o que Berossos representava para a história da Anatólia e Ctésias de Cnido para a história da Mesopotâmia no período helenístico (KNIPPSCHILD 2010, p. 449).

Apesar de muitas outras obras ${ }^{10}$ terem sido escritas por autores gregos e romanos após o desastre de Carras $^{11}$ e o crescente poder dos partos como Império rival de Roma, o trabalho deles difere bastante do feito por Apolodoro. A Parthica de Arriano, por exemplo, uma das mais importantes obras de natureza historiográfica sobre os partos, focou-se nas guerras entre Roma e Pártia, fornecendo frequentemente apenas o ponto de vista dos romanos, hostil aos Arsácidas por razões óbvias. Arriano foi igualmente o responsável por introduzir o que Nikonorov (1998, p. 119) chamou de "teoria falsa da ancestralidade Aquemênida dos reis Arsácidas".

Assim, Apolodoro teria sido o primeiro a registrar a ideologia política parta com relação ao resgate de sua ancestralidade Aquemênida, por volta de 50 a.C., tendo este registro depois penetrado a tradição literária romana, em algum momento entre 117-130 d.C.. Dali em diante, a tradição que remete a Apolodoro na historiografia romana da Pártia se perdeu, o que torna Arriano (c. 130 d.C.) não apenas uma fonte primária importantíssima para a história dos partos, mas também uma sequência lógica na análise da Parthica de Apolodoro.

\section{Arriano de Nicomédia}

Exaltado por muito tempo como fonte mais precisa para a história de Alexandre Magno, Arriano foi aclamado por Fócio (Fócio, Myrobiblion = FGrH 156, F 30), no século IX d.C., como novo Xenofonte. Feito governador da Capadócia em 131 d.C. sob o Imperador Adriano, Arriano mostrou-se preocupado com os domínios orientais do Império Romano. De todas as regiões orientais, a Pártia acabou por ser muito presente em suas obras, da Anábase (sobre as expedições de Alexandre) a uma história específica sobre os partos (objeto principal desta apresentação crítica), sem deixar de ser mencionada na Índica (suplemento da Anábase) e em sua História dos eventos após Alexandre (Ta meta Alexandron). A razão é simples: nascido como um "reino obscuro" nas fronteiras do Império Romano, o Império Parto rapidamente transformou-se no principal adversário dos romanos no oriente, situação que resultou em diversas expedições militares lideradas por generais romanos, incluindo Marco Antônio, Nero e Trajano (STADTER 1980, p. 135).

\footnotetext{
${ }_{10}$ Exemplos são: Quinto Délio (I a.C.), Arriano (II d.C.; cf. infra) e Asínio Quadrato (III d.C.). Cf. Cornell (p. 424-425; 648-654).

${ }^{11}$ Batalha travada entre as legiões romanas de Crasso e os partos, em 53 a.C. Segundo Plutarco (Crasso 33), após a esmagadora vitória parta, a cabeça de Crasso foi exposta na corte inimiga por Jasão, um dos atores que na ocasião encenavam as Bacantes, de Eurípides. Embora apócrifa, a cena da exposição da cabeça de Crasso parecia combinar perfeitamente com o interesse que o rei parto supostamente nutria pelo fim trágico das Bacantes, ao menos no relato criativo do biógrafo grego.
} 
Das obras supracitadas, duas nos chegaram em fragmentos. A primeira delas, a História dos eventos após Alexandre, originalmente escrita em dez livros (cobrindo os eventos de 323 a 321 a.C), foi preservada em um longo sumário preparado por Fócio (Myrobiblion 92) e em outros numerosos fragmentos, organizados e publicados no início do século XX por Jacoby (Fragmente II, pp. 840-51; 872-73; 874; 881-83; cf. CHAUMOND 2011, p. 524). A segunda dessas histórias (Parthica) trata especificamente dos partos, tendo como principal objetivo mapear as fases da expedição de Trajano. ${ }^{12}$

A Parthica não foi apenas o trabalho mais longo de Arriano, mas também o que mais possibilidades fornecia no que diz respeito à abordagem utilizada. Com efeito, Arriano poderia ter escrito uma etnografia histórica da Pártia, ou seja, ter feito, como de costume no gênero, uma descrição da geografia e do clima da Pártia, seguida de um relato geral de seu povo (origens, tradições, costumes etc.) e de uma narrativa sobre seus reis e as guerras travadas (cf. DENCH 2007, p. 499-500 para uma discussão menos específica sobre a relação entre etnografia e historiografia). Esse tipo de estudo teria como principais representantes Heródoto (especialmente seu livro sobre o Egito), Ctésias, Manetão e Berossos (STADTER 1980, p. 135).

Na Índica, por exemplo, Arriano realizou uma espécie de "versão comprimida desse esquema", apresentando o território e seu povo na sequência tradicional descrita anteriormente:

Devo chamar de Índia as partes situadas a leste do Indo, e seus habitantes de indianos. Extrema ao norte da Índia o monte Tauro, embora assim não o seja chamado na região. O Tauro tem início no mar, oposto aos territórios da Panfília, da Lícia e da Cilícia, e se estende até o mar oriental, atravessando toda a Ásia. Mas a montanha tem diferentes nomes em diferentes lugares [...] (Arriano, Índica 2 = Anábase VIII, 2).

Megástenes afirma que há cento e dezoito tribos indianas. Que há muitas tribos, concordo com Megástenes; mas não posso compreender como ele soube e registrou seu número exato, considerando que sequer visitou qualquer parte digna de nota da Índia e que esses diferentes povos não possuem muito trânsito uns com os outros. Os indianos, ele diz, eram originalmente nômades, como o são os citas pouco inclinados à agricultura, que andando sem destino com suas carroças habitam partes da Cítia; do mesmo modo, os indianos também não possuíam cidades e não construíam templos, servindo-se de peles de animais mortos na caça como indumentária e alimentando-se de cascas de árvores (Arriano, Índica 7 = Anábase VIII, 7).

Assim que deixou a Índia, após tomar essas medidas, [Alexandre] coroou Espatembas, um dos seus Companheiros, por ser o mais versado nos ritos báquicos; quando Espatembas morreu, seu filho reinou em seu lugar; o pai fora rei da Índia por cinquenta e dois anos; o filho, por vinte anos. Quando o último morreu, seu filho subiu ao poder, e muitos dos seus descendentes receberam o reino em sucessão, tendo sempre o filho sucedido ao pai (Arriano, Índica 8 = Anábase VIII, 8).

${ }_{12}$ Esquema inspirado na organização do conteúdo feita por Chaumond (2011, p. 524). 
Aparentemente, Arriano seguiu, na Parthica, essa tradição literária de etnografias históricas helenísticas (cf. livro I no esquema da Parthica), como havia feito em sua Índica, mas sem ignorar elementos de uma narrativa de memórias da guerra (a exemplo de César e outros generais romanos antes dele) e de um relato encomiástico dos triunfos de Trajano (STADTER 1980, p. 136). Com efeito, ao considerar o sumário dos livros da Parthica (cf. supra), torna-se claro que Arriano pretendia escrever um trabalho monográfico com uma descrição de toda a trajetória das relações diplomáticas e militares romanas e partas, começando com o fiasco de Crasso na batalha de Carras (53 a.C.), passando por Marco Antônio, Augusto, Tibério, Cláudio e outros imperadores, e finalizando com a atuação militar de Trajano. Arriano pretendia, assim, colocar o conflito entre os dois Impérios em perspectiva.

Outra área de interesse de Arriano, e que provavelmente marcou sua Parthica, era a exaltação de Trajano como um novo Alexandre (cf. BOSWORTH 2007 , p. 448 para a admiração de Trajano por Alexandre). Isto é possível de se argumentar com base em duas estratégias investigativas: 1 ) a comparação entre as apreciações filosóficas do desejo de conquista de Alexandre e Trajano, feitas por Arriano e Dião Cássio; 2) uma análise comparada dos vícios de Alexandre e Trajano, sendo os vícios do último apresentados por Dião Cássio momentos antes de sua narrativa sobre a conquista de Adiabene (distrito que incluía Gaugamela, onde Alexandre derrotara Dario III) (STADTER 1980, p. 140).

A primeira estratégia de investigação remete-nos aos usos de Arriano por Dião Cássio. Salta aos olhos parte da apreciação filosófica de Alexandre por Arriano (Anábase VII, 1-3), após consideração dos planos do rei macedônio:

Quanto ao que pensava Alexandre, vejo-me incapaz de conjecturar com qualquer precisão, nem ouso adivinhar; o que posso asseverar é que Alexandre não possuía más ou pífias intenções, tampouco se satisfaria com as posses até o momento obtidas, nem mesmo se ele tivesse anexado a Europa à Ásia, e a Bretanha à Europa. Ao invés disso, Alexandre sempre teria perseguido o desconhecido por mais distante que estivesse dele, sendo sempre o rival de outrem ou de si mesmo (Arriano, Anábase VII, 1).

Da mesma forma, o ímpeto militar de Trajano (Dião Cássio, História Romana LVIII, durante toda a narrativa sobre a guerra contra dácios, armênios e partos) e sua derrota apenas para a morte (Dião Cássio, História Romana LVIII, 33), e não para um inimigo que pudesse ser vencido pelo homem, tornam sua figura bastante próxima à de Alexandre (a não ser pelos excessos cometidos pelo rei macedônio, excluindo o gosto pelo vinho, que Trajano também compartilhava). Afinal, figuras heroicas teriam apenas a morte como limitação às suas realizações.

Em seguida, deve-se mencionar como segunda estratégia investigativa a análise comparada dos vícios de Alexandre e Trajano, tendo os traços do Imperador romano sido curiosamente apresentados por Dião Cássio (História Romana LXVIII, 7) antes de sua narrativa sobre a conquista de Adiabene.

Segundo Dião Cássio (História Romana LXVIII, 7, 4), Trajano "bebeu todo o vinho que quis em vida, permanecendo, a despeito disso, sóbrio". Seu interesse 
pelo vinho o aproximava imensamente de Alexandre, quando considerados os relatos dos vícios do rei macedônio em diversas fontes, de Quinto Cúrcio (História de Alexandre $\mathrm{V}, 7$ ) a Arriano (Anábase IV, 8), que atribui as causas do assassinato de Clito ao insulto dirigido por ele ao rei e ao fato de o último ter se tornado "escravo de dois vícios, pelos quais nenhum homem deveria se deixar vencer: a paixão e o alcoolismo". Aqui, a diferença entre Trajano e Alexandre seria a capacidade do primeiro em não se tornar escravo de seu vício. A Parthica de Arriano, portanto, mesclava uma história dos conflitos entre romanos e partos, postos em perspectiva, e o elogio dos feitos de Trajano, um novo Alexandre em alguns aspectos, em sua campanha nas fronteiras orientais do Império.

\section{Conclusão}

Dentre as muitas fontes para a história do Império Parto, duas foram destacadas neste artigo, por serem de suma importância na constituição, já na Antiguidade, de tradições literárias sobre os Arsácidas. A primeira delas é Apolodoro de Artemita, o historiador mais antigo a denunciar as apropriações partas de sua ancestralidade Aquemênida, como forma de se distanciarem dos Selêucidas e se aproximarem de um passado oriental mais remoto e legítimo, se consideradas as expectativas das elites locais e de seus novos soberanos. Apolodoro foi também o autor de uma Parthica amplamente utilizada como fonte por Estrabão, Pompeu Trogo e, no caso da historiografia romana, Arriano de Nicomédia (autor da outra Parthica produzida nos dois primeiros séculos da era cristã).

270 A segunda delas é, portanto, Arriano, que em sua Parthica narrou a história das relações entre partos e romanos, colocando-as em perspectiva histórica, e registrou os triunfos militares de Trajano. A escolha de Arriano pela Pártia não foi exclusividade dessa obra; com efeito, o pequeno reino oriental que rapidamente se transformou em um poderoso império, rival de Roma, fez-se presente, por razões distintas e de modos variados, na Anábase, na Índica e na História dos eventos após Alexandre.

Arriano foi o principal responsável pela preservação da obra de Apolodoro na tradição literária romana. De fato, apesar de o registro da ideologia política parta com relação ao resgate de seus vínculos artificiais com a dinastia Aquemênida ter penetrado essa tradição literária cerca de quinze anos antes da redação da Parthica de Arriano, o historiador de Nicomédia foi provavelmente um dos últimos autores romanos a ter acesso à chamada "tradição de Apolodoro" (com informações confluentes, dos seguidores do historiador greco-parto a Arriano, na historiografia romana, passando por autores como Ateneu, Estrabão e Pompeio Trogo; cf. supra).

O valor das obras de Apolodoro e Arriano sobre os partos, portanto, não pode ser subestimado. Não só a Parthica escrita pelos dois em momentos distintos influenciou autores antigos posteriores, cujas obras nos fornecem informações bastante preciosas, por exemplo, sobre a geografia do Irã antigo (cf. Estrabão), como também assegurou que estudos historiográficos pudessem ser desenvolvidos sobre eles, trazendo para o debate questões de método e de natureza das fontes historiográficas analisadas. 


\section{Parthica}

Livro I

Livro II

Livro III

Livro IV

Livro $\mathrm{V}$

Livro VI

Livro VII

Livro VIII

Livro IX

Livro $X$

Livros XI - XVI

Livro XVII
Origem e costumes dos partos; os primeiros Arsácidas

Crasso e a batalha de Carras (53 a.C.)

A invasão da Média por Marco Antônio Pártia e Roma nos governos de Augusto, Tibério e Cláudio

Campanha de Córbulo (c. 7 - 67 d.C.) na Armênia

Pártia e Roma sob os Flávios

Campanha armênia de 114 d.C.; relações do Imperador romano com os aspirantes ao trono parto, Partamásiris e Axídares

Campanha mesopotâmica de 114115 d.C.; registro do percurso militar de Trajano, de Edessa à Babilônia

Tomada de Ctesifonte; avanço da frota romana no Tigre, em direção ao Golfo Pérsico; sucessos militares efêmeros dos romanos; regresso a Ctesifonte e à Babilônia (116 d.C.); revolta dos príncipes partos e armênios, envolvendo o rei armênio Sanatruk.

Cerco de Hatra; eventos posteriores até o retorno para a Síria

\section{Referências bibliográficas}

BEHR, Arnold. De Apollodori Artamiteni reliquis atque aetate. Strasbourg: Nabu Press, 2010 [1888].

BOSWORTH, A.B. A Historical Commentary on Arrian's History of Alexander (Books I-III). Oxford: Clarendon Press, 1980.

Arrian, Alexander, and the pursuit of Glory. In: MARINCOLA, John (org.). A Companion to Greek and Roman Historiography, v. 1. Malden, Oxford: Blackwell, 2007, p. 447-453.

BRUNT, Peter. Arrian. Anabasis of Alexander, 2 vols. Cambridge, Mass.: Harvard University Press, 1976-1983.

CHAUMOND, M.L. Apollodorus. In: Encyclopaedia Iranica Vol. II, Fascículo 2, 2011 [1986], p. 160-161. 
Arrianus. In: Encyclopaedia Iranica. Vol. II, Fascículo 5, 2011 [1986], p. 523-524.

CHRISTENSEN, Arthur. L'Iran sous les Sasanides. Copenhagen: Levine \& Munksgaard, 1944.

CORNELL, Timothy. The Fragments of the Roman Historians. Oxford, New York: Oxford University Press, 2013.

CURTIS, Vesta; STEWART, Sara (orgs.). The Idea of Iran: The Age of the Parthians. London: IB Tauris, 2007.

DABROWA, Edward. The Arsacids and their State. In: ROLLINGER, Robert et al. Altertum und Gegenwart. 125 Jahre Alte Geschichte in Innsbruck. Innsbruck: Studienverlag, 2012, p. 21-52.

DARYAEE, Touraj. The study of ancient Iran in the twentieth century. Iranian Studies, v. 42, n. 4, p. 579-589, 2009.

DEBEVOISE, Neilson. A Political History of Parthia. Chicago: University of Chicago Press, 1938.

DENCH, Emma. Ethnography and History. In: MARINCOLA, John (org.). A Companion to Greek and Roman Historiography, v. 1. Malden, Oxford: Blackwell, 2007, p. 493-503.

HERZFELD, Ernst. Iran in the Ancient East. New York: Oxford University Press, 1941.

HENNING, W. B. Mitteliranisch. In: HOFFMANN, Karl (org.). Handbuch der Orientalistik Iranistik, IV, I. Leiden: Brill, 1958, p. 20-130.

HOLT, Frank. Thundering Zeus. The making of Hellenistic Bactria. Berkeley, Los Angeles, London: University of California Press, 1999.

JACOBY, Felix et al (orgs.). Die Fragmente der griechischen Historiker. Leiden/Berlin, 1923-

JONES, Horace. Strabo. Geography, 8 vols. Cambridge, Mass.: Harvard University Press, 1917-1932.

KNIPPSCHILD, Silke. Literature in Western Asia. In: CLAUSS, James; CUYPERS, Martine (orgs.). A Companion to Hellenistic Literature. Malden, Oxford, Chicester: Blackwell, 2010, p. 448-462.

MASSON, Vadim. Das Land der tausand Stadte. München: Udo Pfriemer, 1982.

NIKONOROV, Valerii. Apollodorus of Artemita and the date of his Parthica revisited. In: DABROWA, Edward (org.). Ancient Iran and the Mediterranean World. Proceedings of an international conference in honor of Professor Józef Wolski. Cracow: Jagiellonian University Press, 1998, p. 107-122.

OLMSTEAD, Albert. History of the Persian Empire. Chicago: University of Chicago Press, 1959. 
OLSON, S. Douglas. Athenaeus. The Learned Banqueters, 8 vols. Cambridge, Mass.: Harvard University Press, 2007-2012.

PEARSON, Lionel. The Lost Histories of Alexander the Great. New York: American Philological Association; Oxford: Blackwell, 1960.

STADTER, Philip. Arrian of Nicomedia. Chapel Hill: University of North Carolina Press, 1980.

TARN, William. The Greeks in Bactria and in India. Cambridge: Cambridge University Press, 1938.

WALBANK, Frank. Polybius. Berkley and Los Angeles: University of California Press, 1990.

WIDENGREN, Geo. Sources of Parthian and Sasanian History. In: YARSHATER, Ehsan (org.). The Cambridge History of Iran: The Seleucid, Parthian and Sasanian Periods. Cambridge: Cambridge University Press, 2007, p. 1261-1283. 